\title{
Urgent Evaluation for TIA - Would it Make a Difference?
}

Can. J. Neurol. Sci. 2009; 36: 403-404

The concept of brief neurologic symptoms due to cerebral ischemia was mentioned as far back as the 19th century. In his presentation "Intermittent Cerebral Ischemia" at the Cerebral Vascular Disease Conference in New York in 1958, Dr. C. Miller Fisher first described these as lasting “...from a few seconds up to several hours." Since the 1960s, the classical definition of transient ischemic attack (TIA) has been a clinical one, focusing on neurologic symptoms lasting less than 24 hours with no apparent nonvascular cause. ${ }^{2}$ It was not until earlier this decade that we have come to appreciate that TIA is not a benign disorder. ${ }^{3,4}$

Stroke risk after TIA ranges from $5-10 \%$ within 48 hours,, 3 $7-9 \%$ within the first week, ${ }^{4,6}$ and $10-20 \%$ within 90 days., Emergent evaluation and treatment of these patients can maximize the potential to prevent subsequent strokes. ${ }^{8}$ Based on current data, all essential work-up should be completed ideally within the first 48 hours. However, not all patients with TIA have a high risk for early stroke. Researchers continue to seek ways to optimize the cost-to-benefit ratio for urgent treatment, including developing and incorporating prognostic scores into clinical practice, carrying out urgent evaluation in an outpatient versus inpatient setting. ${ }^{8-11}$ Many have argued for urgent evaluation of TIA, but data to support that such urgency would alter clinical outcome are scarce.

In this issue, $\mathrm{Wu}$ et al examined whether admitting patients with high risk TIA to a rapid evaluation unit affects their clinical outcomes and costs of care as compared to a historical cohort of other high risk TIA patients. ${ }^{12}$ All 189 patients admitted to the rapid evaluation unit presented within 24 hours of TIA and had symptoms consistent with either a hemispheric event or monocular blindness. From the historical cohort, there were 392 patients who met the same criteria as those admitted to the rapid evaluation unit.

Comparing these two groups, the authors found that those who were admitted were more likely to undergo imaging evaluation such as echocardiogram, MRI, MR angiogram, CT angiogram, and carotid ultrasound. A greater number of patients from the rapid evaluation unit were identified with carotid stenosis, and had carotid endarterectomy or angioplasty. In addition, those who were admitted to the rapid evaluation unit were also more likely to be discharged on a new treatment such as anti-hypertensive or cholesterol-lowering agents. The 90-day stroke risk was significantly lower for the patients who were admitted compared to historical controls $(4.7 \%$ vs. $9.7 \%$, $\mathrm{p}=0.05$ ). Using multivariable analysis and controlling for known differences between the two groups, the authors found that admission to a rapid evaluation unit was associated with a decreased early stroke risk (OR 0.43, p=0.029).

Although this was not a randomized trial, the study findings are important. They not only substantiate the need to formalize the process and timing of an urgent evaluation after TIA, but also show that treating TIA urgently could lead to a significant reduction of future strokes. It is unlikely that the act of admitting someone with a TIA would lower the early stroke risk, but it is rather the aggressive care that takes place during the hospitalization. More imaging studies were performed in admitted patients. More carotid stenosis was diagnosed. Those who were admitted and were found to have carotid stenosis not only were more likely to receive carotid interventions, but also to undergo them sooner. Nearly $50 \%$ of patients from the historical cohort received their carotid intervention after they had suffered a stroke following their TIA. Performing carotid endarterectomy sooner after a TIA has been reported to be associated with a lower risk of recurrent stroke. ${ }^{13} \mathrm{Wu}$ et al found that the early stroke risk was $5 \%$ in those admitted to the rapid evaluation unit with carotid stenosis compared to $26 \%$ in historical controls $(\mathrm{p}<0.019) .^{12}$

An urgent evaluation will likely raise the initial costs of care. In addition, it may not be feasible currently in many practices given limited resources (such as availability of neuroimaging at night or over the weekend). Some practices would need substantial resources to set up an infrastructure that could accommodate urgent assessment. As found in this study by $\mathrm{Wu}$ et al, the one year median costs were significantly greater for the rapid evaluation group (CAN\$8360) than for the historical controls (CAN\$4820). ${ }^{12}$ However, the total lifetime cost of care for stroke survivors is already a huge burden on many healthcare systems. A successful stroke prevention strategy such as urgent evaluation and treatment of high risk TIA may prove to be highly cost-effective. A formal cost-effectiveness analysis will need to be carried out in future studies.

Although most experts would agree that there is a need to expedite assessment and management of TIA, translating research into practice is not straightforward. Who should receive what, where and when remains unclear to many physicians including vascular neurologists. Current data seem to indicate that TIA patients with higher ABCD2 scores and symptoms of a hemispheric event are at higher risk. What should constitute an urgent work-up is still unclear. In appropriate patients, an emergent carotid evaluation followed by an urgent carotid intervention may be justified. The benefit of hospitalizing patients with TIA remains controversial, but it should be considered if it facilitates a more timely work-up. There is a substantial stroke risk within 24-48 hours after TIA; therefore it is crucial that an evaluation be completed during this timeframe. Further studies are needed to confirm the results from $\mathrm{Wu}$ et al, but their work should prompt us to examine the different settings and strategies for carrying out an urgent evaluation after TIA because urgency could lead to significant reduction in stroke burden.

Mai N. Nguyen-Huynh San Francisco, California, USA 


\section{REFERENCES}

1. Fisher CM. Intermittent cerebral ischemia. Cereb Vascu Dis. 1958: 81-97.

2. Siekert RG, Whisnant JP, editors. Cerebral vascular diseases: fourth conference. New York: Grune \& Stratton; 1965.

3. Johnston SC, Gress DR, Browner WS, Sidney S. Short-term prognosis after emergency department diagnosis of transient ischemic attack. JAMA. 2000;284:2901-6.

4. Lovett JK, Dennis MS, Sandercock PA, Bamford JM, Warlow CP, Rothwell PM. Very early risk of stroke after a first transient ischemic attack. Stroke. 2003;34:e138-40. Epub 2003 Jul 10.

5. Correia M, Silva MR, Magalhaes R, Guimaraes L, Silva MC. Transient ischemic attacks in rural and urban northern Portugal: incidence and short-term prognosis. Stroke. 2006;37:50-5. Epub 2005 Dec 1.

6. Kleindorfer D, Panagos P, Pancioli A, Khoury J, Kissela B, Woo D, et al. Incidence and short-term prognosis of transient ischemic attack in a population-based study. Stroke. 2005;36:720-4. Epub $2005 \mathrm{Feb} 24$

7. Hill MD, Yiannakoulias N, Jeerakathil T, Tu JV, Svenson LW, Schopflocker DP. The high risk of stroke immediately after transient ischemic attack. Neurology. 2004;62:2015-20.
8. Rothwell PM, Giles MF, Chandratheva A, Marquardt L, Geraghty $\mathrm{O}$, Redgrave JN, et al. Effect of urgent treatment of transient ischaemic attack and minor stroke on early recurrent stroke (EXPRESS study): a prospective population-based sequential comparison. Lancet. 2007;370:1432-42. Erratum in: Lancet. 2008 Feb 2;371(9610):386.

9. Johnston SC, Rothwell PM, Nguyen-Huynh MN, Giles MF, Elkins JS, Sidney S. Validation and refinement of scores to predict very early stroke risk after transient ischemic attack. Lancet. 2007; 369:283-92.

10. Nguyen-Huynh MN, Johnston SC. Is hospitalization after TIA costeffective on the basis of treatment with tPA? Neurology. 2005;65:1799-801.

11. Tsivgoulis G, Vassilopoulou S, Spengos K. Potential applicability of ABCD score in triaging TIA patients. Lancet. 2007;369:1082.

12. Wu CM, Manns BJ, Hill MD, Ghali WA, Donaldson C, Buchan AM. Rapid evaluation after high-risk TIA is associated with lower stroke risk. Can J Neurol Sci. 2009; 36:450-5.

13. Rothwell PM, Eliasziw M, Gutnikov SA, Warlow CP, Barnett HJM. Endarterectomy for symptomatic carotid stenosis in relation to clinical subgroups and timing of surgery. Lancet. 2004;363: $915-24$ 